\title{
The Link between English Language Proficiency and Academic Performance: A Pedagogical Perspective in Tanzanian Secondary Schools
}

\author{
Job Wilson ${ }^{1} \&$ Sotco Claudius Komba ${ }^{1, *}$ \\ ${ }^{1}$ Department of Social Sciences, Sokoine University of Agriculture, Morogoro, Tanzania \\ *Corresponding author: Sotco Claudius Komba, Department of Social Sciences, Sokoine University of Agriculture, \\ Morogoro, Tanzania E-mail: sotratz@yahoo.com
}

Received: September 18, $2012 \quad$ Accepted: October 22, $2012 \quad$ Online Published: December 2, 2012

doi:10.5430/wjel.v2n4p1 URL: http://dx.doi.org/10.5430/wjel.v2n4p1

\begin{abstract}
English, the Language of Instruction (LOI), has fallen victim of blame of some scholars as the cause of poor performance in secondary schools in Tanzania. The blame is directed at English strongly up until recent years (2010 and 2011) when the results of national examinations have been extremely worse. It seems, the public presumes that there is relationship between students' academic success and their abilities in the LOI. This paper sought to investigate whether there is relationship between English Language Proficiency (ELP) and academic performance in Tanzanian secondary schools. The data used were obtained by administering an ELP test and a review of students' reports, and were quantitatively analyzed using a computer software, Statistical Package for Software System (SPSS) version 18. The study revealed that there is a significant weak positive relationship between ELP and students' academic achievement. The relationship was significant in English and insignificant in other subjects which were investigated. On the basis of the findings of this study, it is argued that academic success is a function of several variables and not only proficiency in the LOI. It is therefore recommended that the responsible authorities should invest in improving English language proficiency among students since ELP is positively connected with academic success.
\end{abstract}

Keywords: English language proficiency; Academic performance; Academic achievement

\section{Introduction}

Tanzania like other multilingual communities globally has not eluded the problem of language of education. The Language of Instruction (LOI) nearly 50 years now since independence has always been a matter of public raging debate. This being the case, the poor performance of students in their academic achievement in their national examinations, for many years has been directed to low proficiency of the LOI which is English. This has been considered to be the major cause of not only the decline in academic achievement but also the general falling of the standards of education. Indeed, proficiency in the LOI is an important factor in educational performance. Despite the presence of some few studies in Tanzania that show, in some way, the connection between LOI and academic performance, there is still a misunderstanding and disbelieve on the existence of connection between test scores and actual performance. Judging from the work, underperformance of the graduates, the general public, which is the final consumer of the services provided by the former, have often failed to see the connection between graduates' actual performance and scores shown in the certificates/ transcripts of these graduates.

Students' success in school depends upon their being proficient in the LOI (Wilkinson \& Silliman, 2008). The LOI plays a crucial role in learning, as Malekela (2003) argues, if the learner is handicapped in the LOI, then, learning may not take place as the instructor and the learner will not be communicating. Therefore, the overall performance of Tanzanian students depends on the LOI to a great extent. In connection to the relationship between English Language Proficiency (ELP) and academic achievement, it is presumed that students who have high 
proficiency in English are expected to perform well in English as a subject and in other school subjects. In the Tanzanian situation, this is not unlike saying low ELP is tantamount to poor performance.

Most of the universities in the world and Tanzania in particular require students to enter the university with a basic level of competence in four distinct English language skills: reading, speaking, writing and listening. The ELP of the prospective students or the incoming university students is therefore a critical determinant in predicting their success in graduate studies at universities. The only difference between overseas universities and Tanzanian universities on proficiency testing is that ELPT in Tanzania is for placement purposes or screening purposes while in overseas is for admission. In the country, some of the public universities like Sokoine University of Agriculture (SUA) conduct English Language Proficiency Tests (ELPTs) and aptitude tests to prospective first year University students as they join their prospective universities. This is done for screening purposes on assumption that proficiency in English language has a significant relationship with the student's academic achievement. This study therefore aims at investigating whether the Language Proficiency Tests (LPTs) given to prospective university students have any relationship with subsequent performance.

The concepts academic achievement (Note 1) and language proficiency are broad. According to this study, academic achievement is delimited to mean the result of academic work undertaken by a student and is defined as the ability to display through speaking or writing what one has learnt in the classroom. On the other hand, language proficiency is delimited to mean the overall ability of an individual in language and a test of proficiency is organised basically into listening, reading, writing and speaking skills. In this study, these two concepts are linked up by the word 'relationship'. Relationship means association or connection or correlation between phenomena or variables. While students' general ability can be seen in their performance of different school subjects, the relationship between academic performance and language proficiency is expressed in terms of correlation coefficient (Note 2).

\section{The Problem}

Many students in Tanzania complete various levels with poor grades or scores in English and in other subjects like Mathematics, Physics, Geography and the like. As a result, many of these students resort to reseat again; still as they do that very few become successful to pass and have chances to continue for A-level studies or college education. In 2010 for instance, as Kagashe (2011, p.2A) reports, a total of 397,251 students sat for national examinations, a total of $174,193(43.83 \%)$ of the students failed the examinations, (and that is to say, they scored division zero) and 223,058 which is $56.15 \%$ passed the examinations and that the average pass mark dropped from $52.83 \%$ in 2009 to $50.40 \%$ in 2010 .

This problem of poor performance and decrease of quality of education in Tanzania has received a considerable attention by scholars (Omari, 1995; Osaki, 1999; Wilson, 2011). In the recent years, the performance of students in the CSSE has been the worst in the successive years ( $2010 \& 2011)$. The release of these poor results has fuelled the beginning of fierce discussion and raging debates on the possible causes. In fact, these debates and discussions, has often been ascribed to students' weaknesses in English language through which knowledge in school is transferred to learners.

Basically, most language experts in Tanzania have so far been considering English as a factor for underachievement of most students at higher levels of education because students fail to learn effectively through the sole medium of English. In this case, teachers are forced to use Kiswahili to clarify the lesson (Jones, Rubagumya \& Mwansoko, 1998). Hence, in most of the classes Kiswahili is used unofficially in teaching academic subjects such as English, Biology, Chemistry, General Studies, Mathematics, etc.

Despite the ongoing debates on the LOI in Tanzania and which has been raging on since independence, little is known to researchers on the relationship between ELP and academic performance or on whether scores in English relate to ability in English language. Very little has been investigated to ascertain whether scores the students achieve in language reflect their ability in the language. Many of these few studies realised that English was not making any head way (Jones, Rubagumya \& Mwansoko, 1998; Mvungi, 1982; Roy-Campbell \& Qorro, 1997) and some realised that English was not to be blamed ( Kadeghe, 2000). Therefore, it is the intent of this paper to examine whether English language is a victim of the blame of mass failure that have been occurring in the country for a time now as it is blamed strongly by the public and some scholars. 


\section{Theoretical Underpinnings}

Good performance of students is essential for social and economic development of an individual and society at large. In Tanzania, poor students' academic performance in most secondary schools is currently a growing problem and the issue is well known and has been discussed by many people for a long time (URT, 2008). This has made affluent parents to take their children to private schools and some send their children abroad. In fact, one of the factors frequently mentioned as a cause, is the LOI that students are not proficient in English, making them fail to catch up with the teaching and learning processes.

The increasing failure of students in English language and in other school subjects in secondary schools and the downfall of education has inspired scholarly discussions and studies on the possible factors of such a dismal situation since 1980's. Of course, different studies that have been done reveal that most Tanzanian students have low levels of ELP. Scholars like Mvungi (1982) and Osbiston (1980), argue that proficiency in the LOI is an important factor in education performance and that lack of proficiency in English would result in poor performance in academic subjects. In this perspective, it seems therefore, that because Tanzanian secondary school students have poor ELP that's why they perform poorly in their national examinations. Table1 shows that in 2006 a total of 141,728 students sat for national examinations, out of whom $2.80 \%$ scored division I, $4.25 \%$ division II, $15.03 \%$ division III, $60.73 \%$ division IV and $16.92 \%$ failed. In 2007, 3.31\% of students scored division I, 5.57\% division II, $14.63 \%$ division III and $62.64 \%$ division IV while $13.85 \%$ were failures. The data shows clearly that the general performance in the CSEE was poor in both years. The majority of the candidates scored Division IV which is the marginal pass and the rest scored Division 0 or "Failed". When the two grades (Division IV and Division 0) their percentages are combined form $77.65 \%$ in 2006 and $76.49 \%$ in 2007 of candidate failed.

Table 1: Form IV NECTA Results by Division, 2006-2007

\begin{tabular}{cccccccc}
\hline Division & Year & Boys & \%-age & Girls & \%-age & Total & \%-age \\
\hline I & 2006 & 2,858 & 3.80 & 1,053 & 1.63 & 3,911 & 2.80 \\
& 2007 & 4,349 & 4.40 & 1,900 & 2.12 & 6,299 & 3.31 \\
II & 2006 & 4,229 & 5.62 & 1,713 & 2.66 & 5,942 & 4.25 \\
& 2007 & 7,152 & 7.23 & 3,353 & 3.74 & 10,505 & 5.57 \\
III & 2006 & 13,462 & 17.88 & 7,917 & 12.29 & 21,379 & 15.30 \\
& 2007 & 16,853 & 17.04 & 10,741 & 11.97 & 27,594 & 14.63 \\
IV & 2006 & 43,599 & 57.90 & 41,255 & 64.02 & 84,854 & 60.73 \\
& 2007 & 58,295 & 57.95 & 59,866 & 66.71 & 118,161 & 62.64 \\
\multirow{3}{*}{ Failed } & 2006 & 11,148 & 14.81 & 12,500 & 19.40 & 23,648 & 16.92 \\
& 2007 & 12,247 & 12.38 & 13,881 & 15.47 & 26,128 & 13.85 \\
\hline
\end{tabular}

Source: NECTA Examination Statistics 2008

For a long time in Tanzania, as noted above, English language has been pinpointed as the major source of underachievement of students. The 2010 CSEE results have been the worst so far ever realised; consequently, this has prompted fierce discussions on the possible causes. According to Msongo (2011, p.3A) most students fail the CSEE because they are not proficient in the LOI as a result they become educated but not knowledgeable. It is clear that if the language of instruction is not understood no or little learning takes place. As a result, our schools and colleges end up producing individuals who are less competent in the labour market.

The problem is not restricted only to secondary schools where English is the LOI but also to primary schools where Kiswahili is the LOI. The Ministry of Education and Vocational Training (MoEVT) is set to launch an in-service training programme for English and Mathematics subjects to mitigate poor performance of pupils in primary schools (Simbeye, 2010, p.3A). This really raises questions as to whether English is the genuine cause of poor performance as it is strongly blamed. One would expect primary school students to perform well because they are taught in Kiswahili but this has been not the case.

Most studies have shown that most of the teaching in Tanzanian secondary schools is unofficially conducted in Kiswahili. Teachers give their lessons in Kiswahili, and then proceed to write notes in English for students to cram/memorize (Criper \& Dodd, 1984; Mwisheikhe, 2003). The problem has been so serious that some scholars 
argue that the standard of education is falling because our children are forced to receive instruction in an alien language (Mwansoko, 1996, p.6 B). It is perplexing to see English being blamed for all the problems existing in the educational sector. Therefore, English to a large extent is thought to be responsible for the much fallen standards. However, the down fall of standard of education cannot be attributed by LOI alone, for in making the goal of education attained there many factors that merge up and these factors range from human resources, infrastructure, learning material etc.

In recent years, there has been an increasing need for Tanzanian students to go to study overseas. In this respect, ELP has been a requirement for admission. Hence, on application Tanzanian students, as it is to others from nonEnglish speaking countries have to provide evidence of proficiency in English before being admitted. Therefore, Tanzanians applying for studies overseas take TOEFL or IELTS for admission into universities in the United States and the United Kingdom respectively.

Much of the literature in the area of the predictive validity of language tests, done in countries of America, Europe and Asia; suggest that ELP is the only one among the many factors that affect academic success (Graham, 1987). At the same time, Tonkyn (1995) argues that there is plenty of evidence that language proficiency is an important factor with regard to the academic performance of overseas students. This implies that students who score higher on the standardized English tests like IELTS or TOEFL have greater chances of future academic success. For such reasons, this study used a moderation of TOEFL test in measuring language proficiency because local proficiency test systems are not standard and are mostly grammar based while other skills like speaking and listening are excluded.

Turning to the connection between proficiency in the LOI and academic performance, these two concepts are intertwined with the processes of classroom teaching and testing respectively. These two processes cannot be separated; one cannot argue that s/he is only involved in one and not in the other, and in facilitating the two processes language play a pivotal role. Thus, failure to understand the LOI, little or no learning can take place since no communication takes place. In such a situation, there will be reverberations of low achievements in academic performance. Therefore, language proficiency is connected to academic achievement for it acts as the engine in the whole processes of teaching and learning as well as testing.

\subsection{Previous Studies Revisited}

In 1984, Criper and Dodd conducted a study to assess the language proficiency of Tanzanian students at all levels observing whether the level they have would facilitate learning in the medium of English. They found that the level of ELP among most Tanzanian students was so low that it hindered learning at an alarming rate. In the primary level, they found that pupils get less inputs of English, only that which they hear from their teachers in class. More significantly, they found that in primary schools teachers frequently stress on grammar and get pupils to do written exercises on it; oral exercises were lacking and teachers emphasized on reading aloud tasks. Moreover, they found that most of the students enter secondary schools with low level of ELP and consequently, there was a slow improvement in English over four years. As a result, the majority of secondary school students failed to follow instruction in English. For that reason, teachers of other subjects resort to teach in Kiswahili and giving notes in English. At the university level, they also found that the entrants have low language proficiency and this has resulted into many universities in the country to establish a special unit, the Communication Skills Unit, whose function is to teach study skills and remedial English to those in need. They generally found that in all levels the level of ELP was low; therefore, recommended serious steps to be taken to improve ELP among the students in Tanzania.

Next, in 2002, Dooey and Oliver did their study on "the predictive validity of the IELTS test as an indicator of future academic success". Their study aimed at investigating how accurate IELTS is, as a predictor of performance and success in the school of business, science and Engineering. To do this, a small scale quantitative study was carried out amongst first year undergraduate students from diverse non- English speaking background and who were admitted on the basis of their IELTS scores. Their findings showed little evidence for the validity of IELTS of language proficiency as a predictor for academic success, confirming previous research findings which suggest that language is but one of the many important contributing factors.

Also, in 2009, Fakeye and Ogunsiji did a study on ELP as a predictor of academic achievement among the EFL students. The study examined the extent to which Nigerian secondary school students' proficiency in English relates to their overall academic achievement in Oyo and Osun states of Nigeria. The scholars used ELPTs as a research instrument and the performance of students in the ELPTs was correlated with the students' annual scores in core school subjects like Biology, Mathematics, and English. The study showed that ELP of the students in Nigeria has a significant positive relationship with their overall academic achievement. Therefore on the basis of these findings, 
they recommended that efforts should be directed at making Nigerian students proficient in English as a way of improving their academic performance.

In short, Dooey and Oliver observed that there is no significant relationship between language proficiency and academic achievement; while Criper and Dodd (1984) realised that there is a substantial gap between the students' level of English and the use of English as a tool for studies in Tanzania. On the other hand, Fakeye and Ogunsiji (2009) concluded that ELP has a significant impact on academic achievement. The existence of conflicting findings, calls for further research in the area. Moreover, most of the studies in the area have been done in other parts of the world with reference to Tanzania. Most of the studies conducted in Tanzania that, in some way, relate to the topic are the ones which are based on either Kiswahili or English as a LOI (Jones, Rubagumya \& Mwansoko, 1998; Kadeghe, 2000; Malekela, 2003; Mvungi, 1982). It was therefore, important to investigate the extent to which the ELP of secondary schools in Tanzania relates to the general academic performance.

\section{Methodology}

The study was conducted in Morogoro Urban District, in Tanzania from January to March 2011, involving one government secondary school. The school enrols students from both government and private O- level schools and from different parts of the country. Morogoro Urban is among the fast growing cities in Tanzania. According to URT Census of 2002, the district had the annual growth rate of $2.6 \%$.

The research employed purposive sampling in selecting the students to be involved in the study. The students selected purposely were those whose academic achievement scores of English and General Studies terminal examinations were available in their progress report forms. Those whose test scores were not available in the students' progress reports were not involved. General Studies was used as a representative subject for the other non-selected subjects with a reason that it is the subject which is generally studied by all the students irrespective of whether one is in science or arts streams. Also, Morogoro Urban District was purposely sampled as a study site since the area has a big number of poorly performing schools (URT, 2010).

The study involved both correlational research design and cross- sectional design. Correlational research design was used to assess the degree of relationship between proficiency and academic achievement. The choice of this design was influenced by the nature of assumption at hand. Secondly, the fact that correlational design analyses relationship between two or more variables gave it primary importance. On the other hand, the cross- sectional research design was used because the information about X (Independent Variable) and Y (Dependent Variable) needed to accomplish this study was collected at only one point in time.

\subsection{Participants}

The study involved 89 students and all were from the arts combinations. The A-level students were selected because are prospective University students; after short moment they would be joining various universities nationally or overseas where they can be given ELPTs to ascertain if they could cope with university studies. Again, the Alevel students in Tanzania have a long time of learning in the medium of English, hence were assumed to have enough proficiency and competencies in English. The first researcher's task was to review the students' progress reports so as to get the students' academic achievement scores. Thereafter, the same students whose academic achievement terminal scores were collected sat for a proficiency test. Finally, each student's score of the terminal examinations was correlated with that of proficiency.

\subsection{Data Collection Procedures}

The study employed an ELPT and documentary review methods in the data collection process. To ensure reliability and validity of the data collection instruments, the ELPT was piloted in a private school that is near the field school. The problems realised during a pilot study helped in the adjustment and re-arrangement of questions and phraseology to suit the Tanzanian context. The students' progress reports were reviewed to collect the secondary data for academic achievement scores of English and General Studies. The test for language proficiency was administered to all the sampled students. The ELPT used was a hybrid or a moderation of different TOEFL tests and the justification of doing moderation was that some of the tests involved parts that were difficult to be tested using a pen and paper except through Internet Based Language Testing (IBLT) or computer based systems. Therefore, the aforementioned subject's scores were correlated against the proficiency test scores to determine the relationship and the extent of the relationship. 


\section{Results}

\subsection{Relationship between General Studies, English Achievements and ELP}

Table 2 reveals that there is a significant positive relationship between English achievement scores and English language proficiency (ELP) scores as the correlation coefficient ( $\mathrm{r}$ ) was $=0.293$. This relationship was, however, weak (Note 3). Extending the relationship to other subjects apart from English, General Studies being used to represent other subjects, the results show that there is a slightly weaker positive relationship between these two variables since $\quad r=0.096$. Furthermore, correlating the two subjects (English language and General Studies) it was observed that $\mathrm{r}=0.326$ which is still a weak positive relationship but a bit stronger than that of English achievement and ELP scores.

Table 2: Correlation Analysis of English, General Studies, and ELP

\begin{tabular}{llccc}
\hline \multicolumn{1}{c}{ Variables } & \multicolumn{1}{c}{ Model } & $\begin{array}{c}\text { English } \\
\text { Achievement Test }\end{array}$ & General Studies & $\begin{array}{c}\text { English } \\
\text { Proficiency }\end{array}$ \\
\hline English Achievement & Pearson & 1 & $.326^{* *}$ & $.293^{* *}$ \\
Test & Correlation & & .002 & .005 \\
& sig.(2-tailed) & & 89 & 89 \\
General Studies & $\mathrm{N}$ & 89 & 1 & .096 \\
& Pearson & $.326^{* *}$ & & .372 \\
& Correlation & & 89 & 89 \\
& sig.(2-tailed) & .002 & .096 & 1 \\
& $\mathrm{~N}$ & 89 & & \\
English Proficiency & Pearson & $.293^{* *}$ & 0.372 & 89 \\
& Correlation & & 89 & \\
& sig.(2-tailed) & .005 & & \\
& $\mathrm{~N}$ & 89 & & \\
\hline
\end{tabular}

**. Correlation is significant at the 0.01 level (2-tailed).

Further analysis was done on the relationship between English achievement and language proficiency scores by the use of a scatter plot. A scatter plot helps to see both direction and strength of the relationship. As it is seen from Figure 1 below, the dots form a pattern going from lower left to upper right showing that low scores on one variable are associated with low scores on the other or high scores on one variable are associated with high scores on the other. This relationship is positive; implies that as ELP increases so does academic achievement in English.

Close examination of the plot reveals that the position of each individual on the two tests (ELP and English) is indicated by a single point in the scatter plot and that dots form a line with more scatter, this shows that the strength of the relationship is not much strong.

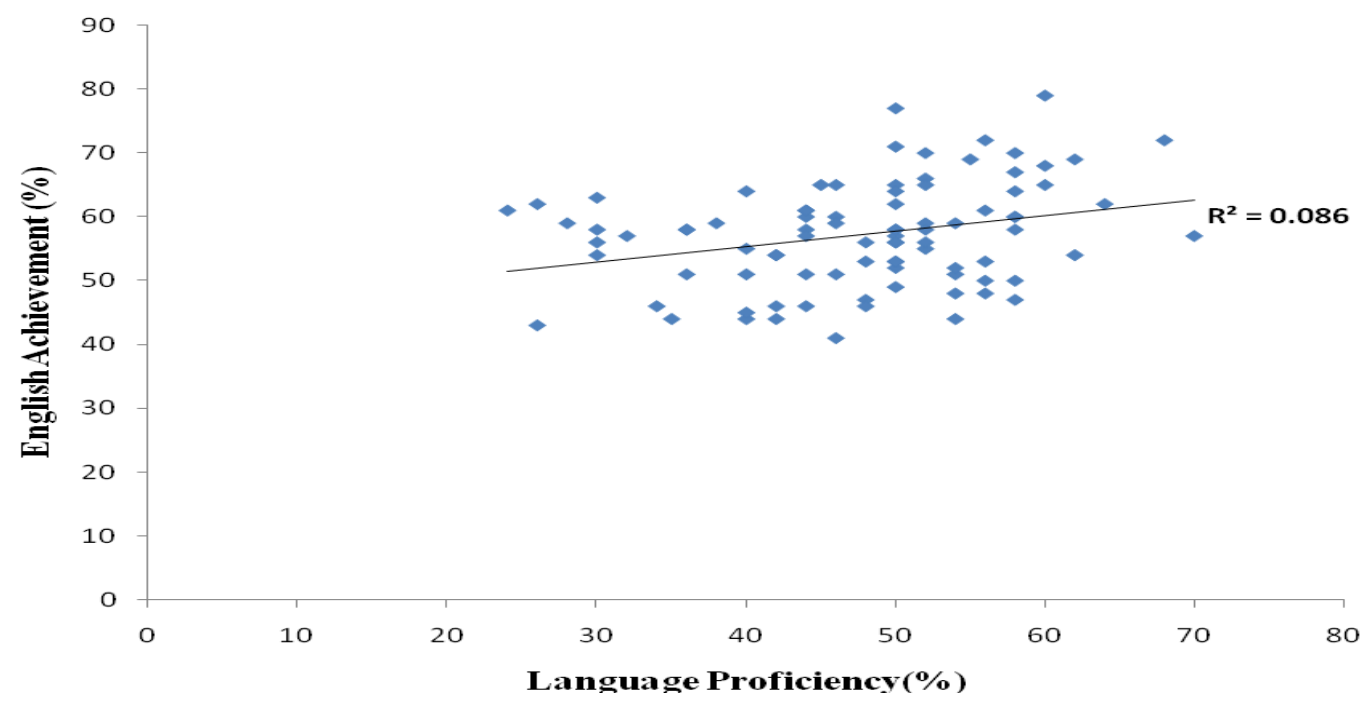

Figure 1: The relationship between English achievement test and language proficiency 
Similarly, correlation analysis of the studied group was narrowed down to the streams that make up the group to explore the combination with a strong and significant relationship between English scores and language proficiency. The findings from the analysis summarised in Table 3 show that in HKL stream $r=0.544$, this is a moderate positive association and the relationship is significant between the two variables and in HGL ' $r$ ' $=0.075$ which is a very weak positive relationship and is insignificant.

Table 3: Combined Tables for Summary of Correlation between English and ELP for each Stream

\begin{tabular}{|c|c|c|c|}
\hline Variables & Model & ELP & Achievement in English \\
\hline \multirow[t]{3}{*}{ ELP for HGL } & Pearson Correlation & 1 & .075 \\
\hline & Sig.(2-tailed) & & .626 \\
\hline & $\mathrm{N}$ & 45 & 45 \\
\hline \multirow[t]{3}{*}{ Achievement in English } & Pearson Correlation & .075 & 1 \\
\hline & Sig.(2-tailed) & .626 & \\
\hline & $\mathrm{N}$ & 45 & 45 \\
\hline Variables & Model & ELP & Achievement in English \\
\hline \multirow[t]{3}{*}{ ELP for HKL } & Pearson Correlation & 1 & $.544(* *)$ \\
\hline & Sig. (2-tailed) & & .000 \\
\hline & $\mathrm{N}$ & 44 & 44 \\
\hline \multirow[t]{3}{*}{ Achievement in English for HKL } & Pearson Correlation & $.544(* *)$ & 1 \\
\hline & Sig. (2-tailed) & .000 & \\
\hline & $\mathrm{N}$ & 44 & 44 \\
\hline
\end{tabular}

** Correlation is significant at the 0.01 level (2-tailed).

\subsection{Relationship between ELP and General Studies}

ELP was correlated with General Studies purposely to ascertain whether there is a relationship to other subjects apart from English. To this end, the correlation of General Studies with ELP portrayed a weak positive relationship by $r$ being $=0.096$ as seen in Table 2 . The variables presented in the study were found to be related. The shown evidence does not favour the assumption that there is no relationship between language proficiency and academic achievement in English and other school subjects in Tanzania secondary schools. Rather, there is strong evidence from the analyses that language proficiency and academic achievement are positively connected. The relationship of these variables is statistically significant when $p<0.01$. The level of significance set was 0.01 and the $p$ - value as shown in Table 2 is 0.005 . Here, p-value is less than the significance level set. Hence, it is established that the relationship is significant. It is therefore, ascertained that there is a significant positive relationship between ELP and academic achievement in English among the studied advanced level secondary school students.

\section{Discussion}

This Study intended to ascertain whether the academic achievement grades Tanzanian students achieve have any relationship with language proficiency. It has been found that there is a significant positive weak relationship between ELP and academic achievement in English and a positive weak relationship in other subjects taught in secondary schools. In contrast, when the relationship was narrowed down to the streams that make up the studied group the relationship was realised to be greater in HKL stream than HGL.

It can be said that there is a weak positive relationship between ELP and academic achievement and that this weak relationship cannot be ignored in English for it is significant at 0.01level and insignificant in other subjects represented by General Studies. It is evident from the study that language plays a role but not a major and dominant role in academic success, and if Tanzania, would improve ELP among other things, students would be successful in their academics. In a way, it is like saying that poor ELP is tantamount to poor academic achievement because of the realised connection between these variables, although the connection is not strong because the non-ELP factors seem to relate or to correlate much with academic success than ELP.

In addition, the results indicate that there is a positive relationship between the language proficiency and 
academic achievement in secondary schools among the studied individuals. Although the relationship is not strong, the direction indicates that students rely on language proficiency to succeed academically. Nevertheless, the positive relationship observed from the study means that the increase of one variable leads to an increase in the other. In other words, the more proficient in English a student is the better he/she is in academics. This implies that if Tanzania will put serious efforts to improve language proficiency in the four skills: writing, reading, listening and speaking, better performance would be expected from the students. On the other hand, a weak positive relationship revealed from the study shows that students do not learn because of their weaknesses in language proficiency. This is to say, the government should devote itself seriously to improve proficiency in English if at all Tanzania wants to continue with English as a LOI, otherwise students will not be learning effectively. Eventually, there will be perpetual poor performance of students as reflected in the 2010 and 2011 national Form Four results.

Moreover, according to these findings, one could be made to believe that poor performance in national examinations is a consequence of poor ELP or it could be true that poor performance and downfall of standard of education in Tanzania is because of using English as the LOI, a language we are not efficient and proficient in. As Mwansoko (1996, p.6 B) argues, the standard of education in the country is falling because our children are being forced to learn in an alien language. However, the realised weak positive relationship help to refute this argument indicating that there other factors that are strong in affecting performance. Proponents of Kiswahili in the country blame English to be the victim of mass failure of students in secondary schools. It is clear now, that the relationship is weak meaning that English should not be blamed strongly as if it is the only factor. The relationship being not strong or not perfect or even average implies that English is one of the factors but the blame are directed at English as if it is the only factor for underachievement. The coefficient of the relationship is weak reflecting that it is the nonlanguage factors that are to a large extent related to poor performance. Thus, English is only one of the factors that can be used in explaining on poor performance of secondary schools in Tanzania., it should therefore, be understood that poor performance is an interplay of several factors and not as how the public sees it, and heaps the blame on English.

It is important to remember that, even where the analysis would have shown a strong perfect relationship, meaning that ELP is strongly correlated to academic performance this would not justify the changing over of the LOI from English to Kiswahili because it is obvious as explained by previous studies (Criper \& Dodd, 1984; Mvungi, 1982) that Tanzanians have low ELP. Thus it would be a correlation of poor ELP score with poor academic achievement scores, culminate to perfect positive relationship which does not mean outstanding performance or extremely good performance. Therefore, the attempt to change the LOI to Kiswahili would take place with no proper attempts of resolving the problem of mass failures because the relationship of these variables being weak. In some way, this study shows that Tanzania in resolving the problem of mass failure should not only keep a glimpse on language but stare beyond language factors when making judgments pertaining to students success in secondary schools as observed that it is the non- ELP factors that seem to be strongly correlated to performance and hence poor performance being described much on the bases of these factors.

It is obviously known that there is no way Tanzania can deny that language is a tool of communication and in a classroom situation, language is pivotal to all activities that are taking place in the class. The world for many years and Tanzania in particular, has been emphasising on a paradigm shift from traditional approaches to modern approaches or student centred methods of teaching and learning. As one would see, the presence of low proficiency in English, the LOI, one would guess what will be the situation when the teacher applies learn centred methods in teaching. Talking from experience as teachers at some time in several secondary schools, English has always acted as bridge and a ridge to participatory methods or learner centred methods of teaching and learning. The experience we have from English classes and Geography classes in secondary schools is that most of students do not participate in discussions most of them remain silent and even if the teacher uses some mechanisms to force them to talk they would only try to speak short utterances.

Basing on the study we can realise that poor performance of students in Tanzania can largely be explained basing on factors other than language; factors like weak foundations from primary level, shortage of teaching and learning materials, teachers, classrooms, offices for teachers, laboratories, latrines and water and electricity. These shortages, together with many others help in explaining the prevailing poor performance in some of the schools in Tanzania.

The findings of this study confirm previous research done in some other parts of the world: USA, Europe, and West Africa to a little extent. The studies generally found a positive correlation (Bellingham, 1993; Cotton \& Conrow, 1998; Fakeye \& Ogunsiji, 2009), and in others a weak positive correlation (Ajibade, 1993; Dooey \& Oliver, 
2002). This study furthermore, shows that proficiency in English has a weak positive relationship with academic performance among the studied advanced level students in Tanzania.

By and large, with regard to the developed assumption the findings of the study can be summarised as follows: First, there is a positive significant weak correlation between ELP and academic achievement in English and a positive insignificant weak relationship in other subjects of the advanced level students. Second, it has been realised that there is more positive correlation between academic achievement in English and ELP than between ELP and other subjects. This means that the association is a bit strong between ELP and achievement in English than in other school subjects like Physics, Chemistry, Mathematics, History, etc. Similarly, when academic achievement in English was correlated with the academic achievement in General Studies, the relationship has been realised to be stronger than any of these academic achievement subjects correlated with language proficiency. Therefore, this shows that what helps students to pass in their academics by large are other factors apart from language, factors like students' discipline, school infrastructures, human resources, materials, learning strategy and testing approaches; in the same way as Biggs (1987) argues that student's approaches to learning are a valued attributes and influence on academic achievement.

\section{Conclusion and Recommendations}

This study has examined and determined the extent of relationship between ELP and academic achievement in Tanzania involving the students of Morogoro Urban District. The results have indicated that there is a positive weak relationship between ELP and academic achievement in English but significant at 0.01 level. In other words, the increase of ELP variable makes improvement in academic achievements. It implies that, the more proficient in English a student is, the better s/he is in academics, though such relationship has been found to be not very strong. When the relationship was extended to other subjects apart from English, the results revealed that it was still weak. Generally, statistical computations have revealed that the variables are related. While the study confirms the positive connection between ELP and academic achievement, many of the correlations that have been done are only at moderate levels $(\mathrm{r}<0.5)$, depicting that there are other possible factors that could be used to predict students' performance besides ELP scores. The study therefore, concludes that academic success is an interplay of several variables and that ELP plays a role in performance but not the major role. On the basis of the results and discussion, it is recommended that Tanzania should adopt English as LOI in primary schools, so that language proficiency is cultivated among the pupils from the initial stages of their education. In addition, given the role of English language in globalization and development, it is advisable for Tanzania to put much emphasis on ELP as an additional criterion for admission into secondary schools and higher education since no single factor can predict performance. O-level and A- level NECTA results alone are not sufficient to predict the success of a student in the higher levels education or in colleges respectively. It is also recommended that the government should invest more in improving students' ELP in the four skills: writing, reading, listening and speaking, in this way, a better performance would be achieved.

\section{References}

Ajibade, A. Y. (1993). Proficiency in English and affective factors as predictors of senior secondary school students' achievement in French. Unpublished PhD Thesis. University of Ibadan, Nigeria.

Bellingham, L (1993). The relationship of language proficiency to academic success for international students. New Zealand Journal of Educational Studies, 30, 229-232.

Biggs, J. (1987). Students' approaches to learning and studying. Melbourne: Australian Council for Educational Research.

Criper, C., \& Dodd, W. (1984). Report on the teaching of the English language and its use as a medium in education. Dar es Salaam: The British Council.

Dooey, P., \& Oliver, R. (2002). An investigation into the predictive validity of the IELTS test as an indicator of future academic success. Prospect, 1, 36-54.

Fakeye, D., \& Ogunsiji, Y. (2009). English language proficiency as a predictor of academic achievement among ELF students in Nigeria. Journal of Science Research, 37, 490-495.

Graham, J. G. (1987). English language proficiency and the prediction of academic success. TESOL Quarterly, 21, 505-21. http://dx.doi.org/10.2307/3586500 
Kadeghe, M. Y. (2000). The implication of bilingual education in learning and teaching: The case of Tanzanian secondary schools. Unpublished PhD Thesis. University of Dar es Salaam, Tanzania.

Malekela, G.A. (2003). English as a medium of instruction in post-primary education in Tanzania: Is it a fair policy to the learners? In B. Brock-Utne, Z. Desai, \& M. Qorro (Eds.), Language of Instruction in Tanzania and South Africa, (pp. 102-111). Dar es Salaam: E\&D Limited.

Msongo, B. (2011). Mhitimu kasoma hajaelimika. Habari Leo, Gwiji la Habari Tanzania(May, $7^{\text {th }}$ ), p3A.

Mvungi, M. M. (1982). Relationship between performance in instructional medium and performance in selected school subjects in Tanzania secondary schools. Unpublished PhD Thesis. University of Dar es Salaam, Tanzania.

Mwansoko, H. (1996). Kiswahili: Should it be used to teach at university? The Guardian(March $2^{\text {nd }}$ ), p 6 B.

Mwisheikhe, H. (2003). Using Kiswahili as a medium of instruction in science teaching in Tanzanian econdary schools. In B. Brock-Utne, Z. Desai, \& M. Qorro (Eds.), Language of Instruction in Tanzania and South Africa, (pp. 129-148). Dar es Salaam: E\&D Limited.

NECTA. (2008). Examination results statistics, cycle 2007. Dar es Salaam, NECTA.

Omari, I. M. (1995). Conceptualizing quality in primary education. Papers in Education and Development, 16, 25-48.

Osaki, K.M. (1999). Science education in secondary schools (SESS): An internal project evaluation commissioned by GTZ. Dar es Salaam: Ministry of Education and Culture and GTZ.

Roy- Campbell, M. Z., \& Qorro, A. M. (1997). Language crisis in Tanzania: The myth of English versus education. Dar es Salaam: Mkuki na Nyota Publishers.

Rubagumya, C., Jones, C., \& Mwansoko, H. (1998). Language for learning and teaching in Tanzania. Dar es Salaam: British Council.

Tonkyn, A. (1995). English language proficiency standards for overseas students who needs what level? Journal of International Education, 6, 37-61.

United Republic of Tanzania (URT). (2002). National Population Census. Dar es Salaam, Government Printers.

URT, (2008). A performance audit report on school inspection programme for secondary schools in Tanzania: A report of the controller and audit general of the United Republic of Tanzania. Dar es Salaam: National Audit Office.

URT, (2010). Basic education statistics in Tanzania 2006 - 2010. Dar es Salaam, MoEVT.

Wilkinson, L., Morrow, L., \& Chou, V. (2008). Improving literacy achievement in urban schools: Critical elements in teacher preparation. Newark: International Reading Association.

Wilson, J. (2011). English language proficiency and academic achievement in Tanzanian secondary schools. Unpublished M.A Thesis, University of Dar es Salaam, Tanzania.

\section{Notes}

Note 1. In this study academic Achievement and Academic Performance are used interchangeably to mean scores or grades achieved or realised by assessing or examining the ability displayed through speaking or writing what one has learnt in the classroom.

Note 2. The term correlation refers to a process of establishing whether or not relationship exists between two variables. It means, as one variable changes, the other also would change in a predictable way and correlation does not mean causation.

Note 3. Weak relationship- is when ' $r$ ' is less than 0.5 which is the average of degree of association 